\section{International Journal of Medical Research and Review}

2019 Volume 7 Number 5 September-October

\title{
Psychiatric manifestations of HIV disease
}

\author{
Rameshboobathi K. ${ }^{\mathbf{1}}$, Rajeshkannan N. ${ }^{*}$ \\ DOI: https://doi.org/10.17511/ijmrr.2019.i05.11 \\ 1 K. Rameshboobathi, Associate Professor, Department of Psychiatry, Government Theni Medical College \& Hospital, Theni, Tamil Nadu, \\ India. \\ 2* N. Rajeshkannan, Senior Resident, Government Institute of Psychiatric Medicine, Research \& Rehabilitation, Theni, Tamil Nadu, India.
}

Background: The appearance of AIDS on the medical and social scene in the early 1980 has been followed by worldwide spread of the disease and escalating numbers of persons affected. the first case was detected in 1984. For the first time in a worldwide epidemic, it has been necessary to try to change fundamental aspects of the human behavior by education and the dissemination of knowledge about psychiatric manifestations. Aim: To find out the psychiatric manifestations of HIV disease. Methods \& Materials: 37 patients and 20 controls were taken up for evaluation of psychopathology. It's a prospective study. Sociodemographic proforma, Socioeconomic Scale, Trail making A \& B tests, color cancellation test, Raven's progressive matrices, Wechsler scale for memory, Linguistic fluency test were used. Results: Persons with HIV were having psychiatric manifestations like, Adjustment disorders, Depression, suicide, schizophrenia, Mild cognitive impairment to Dementia were noted among HIV and associated illnesses. Conclusion: Proper treatment adherence, counselling, follow up will improve the patient's wellbeing.

Keywords: Adjustment disorder, Depression, Dementia, HIV, Mild cognitive dysfunction, Suicide

Corresponding Author

N. Rajeshkannan, Senior Resident, Government Institute of Psychiatric Medicine, Research \& Rehabilitation, Theni, Tamil Nadu, India.

Email: kannan.dr86@gmail.com

\section{How to Cite this Article}

Rameshboobathi K, Rajeshkannan N. Psychiatric manifestations of HIV disease. Int J Med Res Rev. 2019;7(5):422-429.

Available From

https://ijmrr.medresearch.in/index.php/ijmrr/article/ view/1088
To Browse

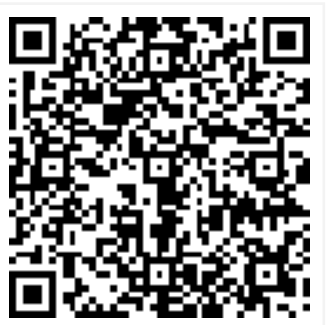

\begin{tabular}{|c|c|c|c|c|}
\hline \multicolumn{2}{|r|}{$\begin{array}{c}\text { Manuscript Received } \\
2019-09-10\end{array}$} & $\begin{array}{c}\text { Review Round } 1 \\
2019-09-20\end{array}$ & $\begin{array}{c}\text { Review Round } 2 \\
2019-09-27\end{array}$ & $\begin{array}{c}\text { Accepted } \\
2019-10-01\end{array}$ \\
\hline \multicolumn{2}{|r|}{$\begin{array}{c}\text { Conflict of Interest } \\
\text { No }\end{array}$} & $\underset{\mathrm{Nil}}{\text { Funding }}$ & $\begin{array}{c}\text { Plagiarism X-checker } \\
7 \%\end{array}$ & Note \\
\hline OPEN & (c) 2019 by r & $\begin{array}{l}\text { vathi, N. Rajeshkanr } \\
\text { iccess article license } \\
\text { https://creativecc }\end{array}$ & $\begin{array}{l}\text { shed by Siddharth Health Research and Social Welfare Societ } \\
\text { eative Commons Attribution } 4.0 \text { International License } \\
\text { licenses/by/4.0/ unported [CC BY } 4.0 \text { ]. }\end{array}$ & \\
\hline
\end{tabular}




\section{Introduction}

In 1981 a group of previously healthy young homosexual men in California and New York presented with features of Pneumocystis pneumonia and Kaposi's sarcoma and was associated with immunodeficiency with low lymphocyte count. Subsequently Human Immunodeficiency Virus (HIV) was isolated in 1983 and subsequent studies established the casual relationship between HIV infection and development of AIDS.

\section{Psychiatric disorders in HIV infection}

A number of clinical psychiatric syndromes have been identified in relation to HIV infection. HIV related brain disorders including AIDS dementia complex, delirium, organic mood disorders and organic personality disorders are often mistaken for stress induced or functional psychiatric disturbance such as reactive depression or anxiety [1]. The symptoms are described in psychiatric terminology as adjustment disorders with depressed and or anxious features. What differentiates AIDS from cancer or other life-threatening illness is the extremely high rate of central nervous system complications that not only impair the individual's ability to cope with the stress but contribute to the production of psychiatric illness. Some common symptoms of adjustment reaction in HIV infected individual, fatigue, anxiety, malaise, worry, memory impairment, anger, slowing of thought, anorexia, apathy, insomnia, social withdrawal, low self-esteem [2]. Depression, suicidal ideas, guilt, hypochondriasis, self-denigration, feeling of isolation, self-blame, depersonalization. Some have physical symptoms of anxiety which mimic the prodromal features of AIDS [3]. Windgasssen 1989 has used the term AIDS induced psychogenic state.

Major depression in HIV infected population is seen at a rate of $5-8 \%$ and is similar to that seen in other chronic medical conditions [4]. A two year follow up study has revealed that $10-25 \%$ of seropositive men report depression during the course of the illness [5]. Number of studies have examined factors associated with distressful reactions and indicate that those with depression or suicidal attempts have past psychiatric history, poor social support, lower education, recent loss and lower internal loss of control.

High prevalence rates (35-40\%) have been reported in India among HIV seropositive individuals, who have been diagnosed with HIV infection.
The factors associated with depression have been presence of pain, concomitant alcohol use, AIDS in the spouse and poor family support [6].

Occurrence of psychotic symptoms prognosticates a poor outcome. In India [7] have reported a case of new onset psychosis with predominant hallucinatory symptomatology. Patients with psychosis and cognitive impairment died early.

The predominance of hallucinatory and delusional symptomatology prominent attentional and informational processing deficit pointed to sub cortical damage. HIV infection carries such enormous upheavals in an infected individual's life, that suicide has considered a natural concomitant.

The high risk of suicides in the period following diagnosis of infection has been emphasized [8]. Factors that lead to suicide at this stage (6 weeks following revelation) are inadequate pre and posttest counseling, the manner in which news is revealed and the availability of emotional support. As a patient's progress in the course of disease and immunosuppression sets in, there is an increase in suicidal ideation.

Presence of dementia and organic brain syndromes also lead to a higher incidence of deliberate selfharm. Prevalence of suicidal attempts in relation to HIV infection has indicated that the rates in HIV infected much higher than the general population but not very different from matched seronegative controls belanging to risk groups.

HIV associated cognitive disorders can be divided into HIV associated mild cognitive disorder, HIV associated dementia and HIV associated delirium [9]. HIV invades the central nervous system fairly easily during the course of infection $[10,11]$ have reported that neuropsychiatric complications occur in at least $60 \%$ of HIV infected patients and may be the first sign of disease in $10 \%$ of the patients. Navia et al (1986) coined the term AIDS dementia complex (ADC) for a complex of cognitive, behavioral and motor dysfunctions frequently present in persons with AIDS [12] reported cognitive impairment in a symptomatic HIV sero positive persons. But, studies [13-15] found occurrence of cognitive impairment in physically asymptomatic sero positive subjects.

The burdens of systemic illness, CNS impairment and multiple medications make the individual with symptomatic HIV disease a pronounced risk for delirium. 
Delirium in HIV disease may present with hyperactive agitated picture or with hypoactive withdrawn features.

\section{Aim}

The aim of the study is to study the prevalence, nature and intensity of psychiatric manifestations in HIV disease and to correlate them with physical variables.

\section{Materials and Methods}

Settings: This study was conducted in Government Theni Medical College and Hospital, Theni. Patients selected from those attending HIV clinic Department (ICTC).

ICTC-Integrated Center for Treatment and Counselling.

Duration \& type of study: This study was conducted from September-2018 to December2018, all the patients in the experimental group were initially screened by attending physician and on his advice were included in the study. It was a cross-sectional, prospective study.

Sampling method: Patients attending HIV clinic were randomly selected after satisfying inclusion criteria. The study conducted with the patients, by a convenience sampling.

The controls were similarly selected among the patient's attenders.

Sample size calculation: A total of 37 patients and 20 controls were chosen. Men were twenty- two and women were fifteen in number. Each patient was explained about the nature of study and willing patients were included in the study.

Inclusion criteria: The following were inclusion criteria:

01. patient should be HIV positive according to WHO criteria

02. Only adults below 60 years were included

03. They should not have suffered significant neurological/psychiatric illness previously.

04. They should not have a history of alcohol or drug dependence.

05. Clinical examination should rule out the possible of secondary neurological complication of AIDS.

06. Patient should be willing and cooperative.
The experimental group was studied in comparison to the control group of individuals from similar ethnic background.

Exclusion criteria: There were chosen from those accompanied the patients. their willingness were sought and they satisfied the inclusion criteria 2,3,4 and 6 .

\section{Data collection procedure}

The following tools were used in the evaluation of patients.

01. Demographic proforma

02. International classification of disease (ICD-10)

03. Socio economic status scale (SES-Gupta and B.B. Sethi-1978)

04. Trail making test $A \& B$ (TMA \& TMB)

05. Color cancellation test (CCT)

06. Raven's progressive matrices

07. Wechsler scale for memory

08. tests for linguistic fluency

Data analysis: The results of the study were analyzed by both qualitative measures and quantitative measures using statistical techniques. Descriptive data were studied, measures of central tendencies and distribution such as range, mean, SD. Discriminative statistics such as student's ' $t$ ' test was used to compare the experimental and control group in their test scores. Correlation studies using Pearson's correlation were done to identify the nature of association between dependent and independent variables.

Ethical consideration \& permission: Hospital Ethical committee approval and written consent of participants obtained.

\section{Results}

For the HIV positive group, 37 patients who fulfilled the inclusion and exclusion criteria were taken. 20 subjects comprised the control group age, education, sex and socio-economic status of both groups are comparable. The age ranged from 21 to 59 years.

21 out of 37 people hailed from urban areas. 23 of patients belongs to lower middle class. One third of patients belong to very low socio-economic status. Almost two third of patients had high school education. 
One third of patients were having not crossed preschool education. $5 \%$ of the patients were unemployed. They were dependent on some of the family members. Nearly two third of patients group belongs to late symptomatic group.

Staging of the illness was done on the basis of clinical feature.

Table-1: Aids defining illnesses in HIV patients.

\begin{tabular}{|l|l|}
\hline \multicolumn{1}{|c|}{ Aids defining illness } & N \\
\hline Tuberculous pericardial effusion & 1 \\
\hline Recurrent diarrhea & 12 \\
\hline Oesophageal candidiasis & 4 \\
\hline Pulmonary tuberculosis & 3 \\
\hline Extrapulamonary tuberculosis lymphadenopathy & 2 \\
\hline Total & 22 \\
\hline
\end{tabular}

Table-2: Duration of awareness of HIV positive status.

\begin{tabular}{|l|l|l|}
\hline \multicolumn{1}{|c|}{ Awareness } & \multicolumn{1}{|c|}{$\mathrm{N}$} & \multicolumn{1}{c|}{$\%$} \\
\hline Below one Year & 18 & 49 \\
\hline Above one Year & 19 & 51 \\
\hline
\end{tabular}

Fifty percent of the individuals have the knowledge about their HIV status for more than 1 year. Assessments of attention, memory, intelligence, language fluency, and new learning ability have shown the following results. (Table $3 \& 4$ )

Table-3: Sub functions of memory among HIV patients.

\begin{tabular}{|l|l|l|l|l|}
\hline \multirow{2}{*}{ Wechsler memory scale } & \multicolumn{2}{c|}{ Range } & \multirow{2}{*}{ Mean } & SD \\
\cline { 2 - 4 } & Maximum & Minimum & & \\
\hline Persons \& current information & 5 & 1 & 3.16 & 1.32 \\
\hline Orientation & 5 & 1 & 4.00 & 1.13 \\
\hline Mental control & 9 & 0 & 5.32 & 2.85 \\
\hline Logical memory & 10 & 0 & 4.21 & 2.71 \\
\hline DF & 7 & 1 & 4.21 & 1.11 \\
\hline DB & 4 & 0 & 2.59 & 0.92 \\
\hline Associate Learning & 7 & 0 & 4.08 & 1.87 \\
\hline Visual reproduction & 10 & 0 & 3.65 & 3.02 \\
\hline
\end{tabular}

$(\mathbf{N}=37)$

Table-4: Comparison of neuropshychological performance of HIV patients and controls

\begin{tabular}{|l|l|l|l|l|l|}
\hline \multirow{2}{*}{} & \multicolumn{2}{|c|}{ Patient } & \multicolumn{2}{c|}{ Control } & \multirow{2}{*}{ T } \\
\cline { 2 - 5 } & Mean & SD & Mean & SD & \\
\hline TMA & 152.59 & 108.25 & 41.36 & 7.5 & $4.57^{*}$ \\
\hline TMB & 687.22 & 337.77 & 157.84 & 38.6 & $6.96^{*}$ \\
\hline CCT & 64.865 & 14.28 & 90.45 & 19.1 & $5.72^{*}$ \\
\hline Memory & 31.35 & 11.13 & 46.81 & 14.86 & $4.86^{*}$ \\
\hline Intelligence & 17.32 & 11.51 & 35.71 & 13.81 & $5.36^{*}$ \\
\hline
\end{tabular}

\begin{tabular}{|l|l|l|l|l|l|}
\hline New learning ability & 2.46 & 2.65 & 5.80 & 1.5 & $5.18^{*}$ \\
\hline Word fluency & 8.51 & 5.83 & 16.95 & 10.92 & $3.82^{*}$ \\
\hline Concept fluency & 15.19 & 5.97 & 14.90 & 6.13 & 0.17 \\
\hline
\end{tabular}

$* \mathbf{P}<0.01$

Patient group and control were compared over neuropsychological performance using student's ' $t$ ' test. Results showed that statistically significant difference in Trail making test, colour cancellation test, memory, intelligence, new learning ability and word fluency between patients and control group. Results indicated that attentional impairment, memory impairment, new learning ability impairment, and impairment in language Fluency in patients were present. Concept fluency was not significantly impaired in the patients.

Table-5: Classification of neuropsychological impairment among HIV patients.

\begin{tabular}{|l|l|l|}
\hline & $\mathbf{n}$ & $\%$ \\
\hline Mild Neurocognitive Disorder & 18 & 49 \\
\hline Dementia & 1 & 3 \\
\hline
\end{tabular}

Eighteen individuals have impairments in cognitive functioning suggestive OF Mild Neurocognitive disorder. Their performance on at least two neuropsychological domains were below. 5 standard deviations, below control norms.

Table-6: Comparison of memory subsets between patients and controls.

\begin{tabular}{|l|l|l|l|l|l|}
\hline & \multicolumn{2}{|c|}{ Patient } & \multicolumn{2}{c|}{ Control } & \multirow{2}{*}{ T } \\
\cline { 2 - 6 } & Mean & SD & Mean & SD & \\
\hline Personal \& current information & 3.16 & 1.32 & 4.2 & 1.2 & $2.92^{*}$ \\
\hline Orientation & 4 & 1.13 & 4.9 & 0.3 & $3.48^{*}$ \\
\hline Mental control & 5.32 & 2.85 & 6.10 & 1.7 & 1.11 \\
\hline Logical memory & 4.22 & 2.71 & 11.68 & 2.6 & $10.06^{*}$ \\
\hline Digit forward & 4.24 & 1.11 & 5.55 & 0.9 & $4.50^{*}$ \\
\hline Digit backward & 2.59 & 0.93 & 3.80 & 0.6 & $5.24^{*}$ \\
\hline Associate learning & 4.08 & 1.88 & 6.55 & 1.1 & $5.39^{*}$ \\
\hline Visual reproduction & 3.65 & 3.02 & 8.5 & 1.4 & $6.78^{*}$ \\
\hline
\end{tabular}

Df $=55 * p<0.01$

Results showed that statistical significance in all memory subtests between patients and controls except in mental control.

Table-7: Correlation between neuropsychological performance and age education awareness and staging of illness

\begin{tabular}{|l|l|l|c|l|l|l|l|c|}
\hline & TMA & TMB & CCT & TM & NLA & INT & WF & CF \\
\hline Age & 0.30 & 0.17 & -0.003 & -0.26 & -0.12 & -0.05 & -0.18 & -0.04 \\
\hline Education & $-0.39 *$ & $-0.62 * *$ & $0.34 *$ & $0.58 * *$ & $0.50 * *$ & 0.29 & $0.58 * *$ & 0.25 \\
\hline Awareness & -0.12 & -0.2 & 0.07 & 0.06 & 0.05 & 0.01 & 0.27 & 0.08 \\
\hline
\end{tabular}




\begin{tabular}{|l|l|l|l|l|l|l|l|l|}
\hline Stage & 0.06 & 0.10 & $0.36^{*}$ & 0.06 & 0.13 & 0.01 & 0.08 & 0.21 \\
\hline
\end{tabular}

\section{Df $=35 * p<0.05 * * p<0.01$}

Results show that education was found to have statistically significant positive correlation with color cancellation test, Weschler memory scale, New learning ability and Word fluency and negative correlation with Trail making test. Staging of illness has statistically significant positive correlation with CCT. Other results are not statistically significant.

Table-8: Correlation
performance
\begin{tabular}{|c|c|c|c|c|c|c|c|c|}
\hline & TMA & TMB & CCT & TM & NLA & INT & WF & CF \\
\hline TMA & - & $0.45 * *$ & $-0.38^{*}$ & $-0.42^{*}$ & -0.24 & $-0.45^{* *}$ & $-0.34^{*}$ & -0.30 \\
\hline TMB & - & - & $-0.70 * *$ & $-0.60 * *$ & $-0.38^{*}$ & $-0.48^{* *}$ & $-0.54 * *$ & -0.32 \\
\hline CCT & - & - & - & $0.52^{* *}$ & 0.3 & 0.35 & $0.46 * *$ & 0.32 \\
\hline TM & - & - & - & - & $0.5 * *$ & $0.67 * *$ & $0.58^{* *}$ & $0.33^{* *}$ \\
\hline NLA & - & - & - & - & - & $0.44^{* *}$ & $0.45^{* *}$ & 0.32 \\
\hline INT & - & - & - & - & - & - & $0.52^{* *}$ & 0.20 \\
\hline WF & - & - & - & - & - & - & - & $0.54 * *$ \\
\hline CF & - & - & - & - & - & - & - & - \\
\hline
\end{tabular}

\section{$\mathrm{Df}=35 * \mathrm{p}<0.05 * * \mathrm{p}<0.01$}

Results show that statistically significant negative correlation of trail making test and all other tests except concept fluency test. Positive correlation of memory and new learning ability intelligence as well as word fluency. Intelligence was positively correlated with word fluency. Result show that attention impairment was negatively correlated with performance in other neuropsychological test. Memory was positively correlated with intelligence, language fluency.

\section{Discussion}

The study was aimed to know the prevalence, nature and intensity of psychiatric manifestation in HIV disease and to correlate them with physical variables. Comparison was made against the seronegative control groups. Physically none of the patient had any evidence of clinical neurological impairment. Whereas major anxiety disorders are more prevalent in HIV population than in the general population, episodes of symptomatic anxiety occur frequently affecting twenty percent of the selected risk groups [12]. The most frequent psychiatric illness found in HIV seropositive subject is adjustment disorders-depressive group. Jacob et al (1991) had reported that adjustment disorders were common in HIV positive subjects found depression, suicidal tendency was present in a considerable number of patients both in the early
And late stage of the disorder [16]. Suicide attempts tend to cluster in the first 6 months after diagnosis, underlining the importance of pre and post-test counselling. Adjustment disorders result from undue concern about uncertainty of life after having been told about the test results. Factors apparently associated with increased risk include social stigma, long-term dependency and the prospect of an inexorable terminal illness.

A considerable proportions of HIV positive people develop psychosis in the context of cognitive impairment or clouding of consciousness, sometimes of a subtle or evanescent nature. It seems unlikely that a specific HIV psychosis exists, but it appears that mania be especially common. Eight such patients, all with cognitive impairment once the florid symptoms had subsided was reported in a previous study. None the patients in the present study evinced psychotic disturbances. In comparison to the matched controls, the sufferers evinced a significantly poor performance in all neuropsychological tests.

Decline in all areas including attention, memory, intelligence, linguistic fluency and concept formation was reflective of decompensation as a precursor of the forth coming neurological damage. In particular impairment of judgment or change of behavior could increase their risk of spreading the infection. The pitfall inherent in attempting to document when these are minor in nature was discussed $[17,18]$. The results raised the possibility that HIV positive asymptomatic persons might have incipient CNS impairment.

The findings were supported by a previous study where a rather larger group was examined and found significant slowing on tests of delayed recall [13]. In this study four patients in the asymptomatic group have shown neuropsychological impairment, suggestive of Mild Cognitive disorder and 14 patients in the late symptomatic disorder.

Martin et al found similar cognitive disturbances. Ricco et al found that poor education was associated with neuropsychological impairment. The results in all neuropsychological tests in this study shows individuals with HIV positive status irrespective of the staging demonstrated a statistically significant impairment [15].

Satz and Coworkers suggested [19] suggested that subtle cognitive deficits might be apparent during the asymptomatic stage, unassociated to neurological changes. 
Previous study has shown that nervous system involvement occurred in the vast majority of men with early HIV infection.

Variation in abnormality with the disease stage was also observed in some cases. In this study, in color cancellation test alone patients belonging to late symptomatic group performed worse than asymptomatic groups. In this study, duration of awareness of illness doesn't influence the performance over neuropsychological tests as well as psychiatric problems found in the patients.

Attention (earliest function to get affected), visuospatial perception, logical memory, visual reproduction, linguistic fluency and new learning ability were the functional systems that were disturbed among these subjects and similar observations were made by previous study [19]. Finally, in this study it was found that early neuropsychological impairment in HIV infection are most evident in individuals with lower cognitive reserve which also observed by Sterret et al.

Limitations: The study was cross-sectional, whereas longitudinal study are needed to determine whether the neurocognitive impairments Leeds to Dementia the study population was small, and hospital based.

\section{Conclusion}

During the study process all the patients in the experimental group were initially screened by senior venereologist on his advice were included in the study. The controls were selected among the patient's attenders, following which all patients were examined by two psychiatrists for neuropsychiatric illness and psychologist for quantification of illness. The present study concludes that psychiatric illnesses like depression and adjustment disorders, neuro-psychological impairments in various domains of cognition such as attention, information procession, memory, intelligence and language fluency are present. Educational status was found to be a protective factor over neuropsychological impairment.

\section{What the study adds to the existing knowledge?}

From the study it was observed that longitudinal studies in the HIV positive group are needed to prove whether the neuropsychological impairment in asymptomatic group progress to Dementia.
Early recognition and appropriate treatment of adjustment disorders will improve the treatment adherence and compliance of HIV positive patients to the therapist.

The study emphasizes the importance of pre and post-test counselling to support the individual and the need for the psychiatrist intervention in the treatment program for HIV Disease.

\section{Author's contributions}

Dr. K. Rameshboobathi: Concept, study design, manuscript preparation.

Dr. N. Rajeshkannan: Concept, study design, manuscript preparation.

\section{Reference}

01. Goethe KE, Mitchell JE, Marshall DW, Brey RL, Cahill WT, Leger GD, et al. Neuropsychological and neurological function of human immunodeficiency virus seropositive asymptomatic individuals. Arch Neurol. $1989 ; 46(2) 129-133$.

doi: $\quad 10.1001 /$ archneur.1989.00520380029008 [Crossref]

02. Goldmier D. Psychosocial aspects of AIDS. $\mathrm{Br}$ J Hosp Med. 1992;37(3)232-240.

[Crossref]

03. Miller EN, Satz P, Visscher B. Computerized and conventional neuropsychological assessment of HIV-1-infected homosexual men. Neurol. $1991 ; 41(10) 1608-1616$.

doi: 10.1212/wnl.41.10.1608 [Crossref]

04. Perkins DO, Stern RA, Golden RN, Murphy C, Naftolowitz D, Evans DL. Mood disorders in HIV infection- prevalence and risk factors in a nonepicenter of the AIDS epidemic. Am J Psychiatry. 1994;151(2)233-236. doi: 10.1176/ajp.151.2.233 [Crossref]

05. Catalan J, Klimes I, Day A, Garrod A, Bond A, Gallwey J. The psychosocial impact of HIV infection in gay men- A controlled investigation and factors associated with psychiatric morbidity. Br J Psychiatry. 1992;161;774-778. doi: $10.1192 /$ bjp.161.6.774 [Crossref] 
06. Brown GR, Rindell JR, Mcmars SE, Kendall SN, Zachary $R$, Temoshok $L$. Prevalence of psychiatric disorders in early stages of HIV infection. Psychosom Med. 1992;54(5)588-601. [Crossref]

07. Sabhesan S, Edwin T, Nammalvar N, Nageswari A. New-onset psychosis in AIDS. Indian J Psychiatry. 1998;40(4)383-385.

[Crossref]

08. Marzuk PM, Tierney $H$, Tardiff $K$, Gross EM, Morgan EB, Hsu MA, et al. Increased risk of suicide in persons with AIDS. JAMA. 1988;259(9)1333-1337. doi: $10.1001 /$ jama.1988.03720090023028 [Crossref]

09. Wiley CA. Pathology of neurologic disease in AIDS. Psychiatric Clin North AM. 1994;17(1)115.

[Crossref]

10. Brew BJ, Rosenblum M, Price RW. AIDS dementia complex and primary HIV brain infection. J Neuroimmunol. 1988;20(2-3)133140.

doi: $10.1016 / 0165-5728(88) 90144-0$ [Crossref]

11. Pajeau AK, Román GC. HIV encephalopathy and dementia. Psychiatr Clin North Am. $1992 ; 15(2) 455-466$.

[Crossref]

12. Atkinson JH, Grant I. Natural history of neuropsychiatric manifestations of HIV disease. Psychiatr Clin North Am. 1994;17(1)17-33. [Crossref]

13. Wilkie FL, Eisdorfer C, Morgan R, Loewenstein DA, Szapocznik J. Cognition in early human immune-deficiency virus infection. Arch Neurol. $1990 ; 47(4) 433-440$.

doi: $\quad 10.1001 /$ archneur.1990.00530040085022 [Crossref]
14. Riedel RR, Helmstaedter C, Bülau P, Durwen HF, Brackmann $H$, Fimmers $R$, et al. Early signs of cognitive deficits among human immunodeficiency virus-positive hemophiliacs. Acta Psychiatrica Scandinavica. 1992;85(4)321326.

doi: 10.1111/j.1600-0447.1992.tb01476.x [Crossref]

15. Lunn, S, Skydsbjerg M, Schulsinger $H$, Parnas J, Pederson C, Mathiesen I. A Preliminary report of the neuropsychological sequeale of human immune-deficiency virus. Arch Gen Psychiat. $1991 ; 48 ; 139-142$.

[Crossref]

16. Perry S, Jacobsberg L, Fishman B. Suicidal ideation and HIV testing. Jama. $1990 ; 263(5) 679-682$.

doi: 10.1001/jama.1990.03440050073036 [Crossref]

17. Stern Y. Neuropsychological evaluation of the HIV Patients. The Psychiatric Clinics of North Am. 1994;17;125-134.

[Crossref]

18. Grant I, Atkinson JH, Hesselink JR, Kennedy CJ, Richman DD, Spector SA, et al. Evidence for early central nervous system involvement in the acquired immunodeficiency syndrome (AIDS) and other human immunodeficiency virus (HIV) infections- Studies with neuropsychologic testing and magnetic resonance imaging. Ann Intern Med. 1987;107(6)828-836.

doi: 10. 7326/0003-4819-107-6-828 [Crossref]

19. Maj $M$, Satz $P$, Janssen $R$, Zaudig $M$, Starace $F$, D'Elia $L$, et al. WHO Neuropsychiatric AIDS study, cross-sectional phase II, Neuropsychological and neurological findings. Arch Gen Psychiatry. 1994;51(1)51-61. doi: $\quad$ 10.1001/archpsyc.1994.03950010051007 [Crossref] 